\title{
CONDUTA ALIMENTAR E SOCIEDADE
}

\author{
FOOD BEHAVIOR AND SOCIETY
}

Neiry Primo Alessi

Docente. Aposentada. Faculdade de Medicina de Ribeirão Preto - USP. Docente e Coordenadora do Sistema de Saúde da Universidade de Uberaba - UNIUBE

CorResPondênCIA: Rua dos Ipês, no 287 Jardim Recreio. CEP 14040-090 - Ribeirão Preto - SP.

Tel: 166308577 - e-mail: luizalessi@convex.com.br

Alessi NP. Conduta alimentar e sociedade. Medicina (Ribeirão Preto) 2006; 39 (3): 327-32.

RESUMO: O artigo parte da concepção que condutas ou padrões alimentares são historicamente determinados.Contextualiza as principais características das fases de desenvolvimento da sociedade brasileira e identifica os valores e normas sociais responsáveis pela conformação de condutas alimentares predominantes em cada uma das respectivas fases.

Destaca como as principais mudanças no mercado de trabalho e nos meios de comunicação de massa, a partir da denominada "terceira revolução industrial", tem contribuído para a formação de hábitos alimentares não condizentes com a atual busca de qualidade de vida.

Descritores: Consumo de Alimentos. Hábitos Alimentares.

\section{1- INTRODUÇÃO}

\section{1- O significado de conduta alimentar}

O tema "Conduta Alimentar e Sociedade", por sua abrangência e complexidade requer que se faça, inicialmente, algumas considerações.

A primeira delas refere-se ao postulado de que a conduta ou comportamento alimentar conforma-se a partir de atos de comer. Como comemos, como preparamos a comida, quando comemos, com quem comemos, o que usamos no preparo, como nos comportamos antes, durante e depois de nos alimentarmos, ou seja, as regras e significados que permeiam todos os aspectos relativos à prática de consumo de alimentos são também socialmente determinados. Esta afirmação não significa não reconhecer as dimensões biológicas, psicológicas, entre outras, que também são constitutivas da conduta alimentar ${ }^{1}$.
Conforme assinalou Contreras (apud Rosales y Figueroa, 1998) ${ }^{2}$ “comer não é e nunca foi uma mera atividade biológica; constitui algo mais do que um simples conjunto de nutrientes eleitos com base numa racionalidade estritamente dietética ou biológica. Comer é um fenômeno social e cultural".

A segunda consideração diz respeito ao fato de no âmbito das Ciências Sociais dispor-se de dois paradigmas para a compreensão da determinação social da conduta alimentar.

O primeiro paradigma, de inspiração positivista, concebe conduta alimentar como comportamento aprendido de modo mecânico e tendo, como características centrais a labilidade e a plasticidade, isto é, as condutas são transitórias e permitem escolhas. A sociedade é concebida como um fato social, o que significa considerar que o homem nasce num meio social já constituído e seus comportamentos são orientados por normas, valores e sanções sociais pré-existentes, 
às quais ele tem que pautar as suas condutas independentemente da sua vontade.

O segundo paradigma, de inspiração holística, concebe conduta alimentar como comportamento social e historicamente construído pelo homem em seus atos de produzir, reproduzir e transformar a sua existência como ser social. A sociedade não é vista como uma entidade que pré-existe ao homem. Ela é concebida como um complexo de relações de interdependência, complementaridade e contradições que permeiam as relações entre os homens, relações essas que se manifestam numa diversidade de instituições sociais (como a família, a escola, a religião, o estado e outras) e nas quais a vida social se processa.

Ambas considerações são importantes de serem destacadas para demarcar os diferentes modos de compreender como atuam os determinantes sociais da conduta alimentar. E é nosso entendimento que a perspectiva holística é a que possibilita uma compreensão mais próxima do real.

Uma terceira e última consideração diz respeito ao fato de os determinantes sociais da conduta alimentar variarem de sociedade para sociedade e mesmo no interior de uma mesma sociedade. Como o nosso interesse está circunscrito na sociedade brasileira é necessário contextualizá-la.

\section{2- O CONTEXTO DA SOCIEDADE BRASILEI- RA}

É sabido que desde suas origens, até os dias de hoje, a sociedade brasileira está estruturada e organizada sob o modo de produção capitalista, cujo desenvolvimento assenta-se em relações de dependência perante as sociedades hegemônicas, a nível mundial.

Do ponto de vista do desenvolvimento econômico a nossa marca central sempre caracterizou-se pelo privilegiamento da produção de produtos direcionados à exportação e, internamente, para a produção de bens duráveis em detrimento da produção de produtos para o atendimento das necessidades básicas da população. Este processo continua sendo possibilitado pela estrutura fundiária que se caracteriza pela concentração de grandes latifúndios em mãos de uma parcela restrita da população e que são utilizados, na sua maioria, para fins de especulação imobiliária e não para a produção de bens de primeira necessidade.

Do ponto de vista social somos uma sociedade estratificada por classe social, no seio da qual manifestam-se e intensificam-se as desigualdades sociais destacando-se os diferenciais de acesso à educação, à saúde, à habitação, ao emprego, à alimentação, entre outros, agravando um conjunto de problemas sociais como a persistência de expressivos grupos sociais sem qualificação profissional, o aumento expressivo da taxa de desemprego, do mercado de trabalho informal, o ingresso da mulher, de crianças e de jovens no mercado de trabalho resultando na intensificação da exploração dos segmentos empregados, o aviltamento das políticas salariais ao lado do agravamento dos mais diversos modos de manifestação da miséria, da violência e da exclusão social.

Do ponto de vista político-ideológico presenciase, cada vez mais, a instituição do Estado Mínimo, em detrimento do Estado de Bem Estar, cujas políticas direcionam-se para o livre jogo das regras dos mercados - notadamente os mercados financeiros -, para o soterramento das noções básicas de cidadania e conformando o cidadão como mero consumidor.

Essas características do processo de desenvolvimento da sociedade brasileira, rapidamente contextualizadas, inserem-se no atual movimento de globalização que, entre outros aspectos, coloca em xeque a centralidade da Nação-Estado estabelecendo referentes que ultrapassam as fronteiras nacionais. A nova territorialidade está marcada pelo mercado global, pela constituição de um imaginário coletivo mundializado e pelo agravamento do desemprego, da miséria, da violência e a persistência de bolsões da fome.

A alimentação, sinônimo de tradição de um determinado território, deixa de estar ao abrigo da fragmentação e da rapidez do mundo contemporâneo. Internacionalizam-se os comportamentos alimentares por meio dos quais os alimentos perdem a fixidez dos territórios e das condutas alimentares.

É neste contexto que se coloca e se compreende a determinação histórico-social da conduta alimentar. Importa destacar alguns desses determinantes, ressalvando que eles não agem isoladamente, mas de modo articulado, conformando e transformando os nossos comportamentos alimentares.

\section{3- AS CONDUTAS ALIMENTARES}

Desde as origens da sociedade brasileira até presentemente o processo de aculturação - que expressa o contato entre diferentes culturas - sempre desempenhou e continua desempenhando importante papel prescrevendo normas e valores orientadores da conduta alimentar. 
Nos primórdios da colonização contatos entre portugueses, grupos indígenas e, posteriormente, grupos africanos foram responsáveis pelo surgimento de condutas alimentares regionais e específicas dos ciclos econômicos que caracterizaram o desenvolvimento e a ocupação inicial do território nacional.

Nos chamados ciclos do Pau-Brasil e da canade-açúcar (período compreendido dos séculos XVI ao XVII) o Brasil era conhecido como a terra da mandioca que, ao lado do feijão, do amendoim, da caça, pesca e coleta de frutos constituíram os alimentos formadores das condutas alimentares dos grupos indígenas: com estes eram preparados a farinha, a tapioca, o beiju que eram consumidos puros ou combinados com carnes, ervas, vegetais, frutos e também utilizados para o preparo de bebidas alcoólicas ${ }^{3}$.

Os colonizadores - conhecidos principalmente por lançarem-se aos mares em busca de especiarias e produtos exóticos - trouxeram para cá bananais, coqueiros, arroz, diversos tipos de carne (bovina, suína, aves) e especiarias como cravo-da-índia, canela, alecrim, erva doce, açúcar e o sal, sendo estes dois últimos produtos desconhecidos pelos índios e escravos.

Os africanos, trazidos ao Brasil na condição de escravos, transportados em péssimas condições e sem os pertences de sua cultura, e as mulheres colocadas na condição de responsáveis pelas cozinhas dos engenhos, passaram a usar apenas de seus conhecimentos culinários influenciando o modo de temperar e preparar os alimentos utilizando ingredientes trazidos pelos portugueses e os usados pelos indígenas.

Do contato entre as diferentes culturas conformaram-se as condutas do uso do sal, ervas, pimenta e do azeite para o preparo, principalmente, do pirão e do angu de mandioca, do feijão cozido com banha e pedaços de porco, o preparo de carnes, preferencialmente, assadas e o uso do açúcar para a confecção de doces caseiros.

Camara Cascudo $(1983)^{4}$ numa passagem de sua obra antológica destaca que os portugueses trouxeram o sal para ser utilizado para conservar as carnes como também difundiram o valor cultural "cozinhar é ter boa mão de sal", valor este que persiste até hoje.

Como exemplos de condutas alimentares deste período e que resistem até presentemente, principalmente nos cardápios regionais, temos o vatapá e o xinxim de galinha; o caruru preparado à base de mandioca e de ervas indígenas e a venda de doces nos tabuleiros expostos nas ruas destacando-se a famosa cocada ${ }^{3}$.

No período conhecido pelos ciclos da mineração, café e borracha (que se estende do final do século XVII até início do século XX ) a ocupação do território nacional deu-se através, principalmente, da extração de pedras preciosas, da borracha e da produção do café, produtos estes destinados à exportação. Neste período presenciamos a vinda da família real para o Brasil, a libertação dos escravos e a chegada de expressivos grupos de imigrantes europeus, fatos que impulsionaram os processos de urbanização, industrialização e do mercado interno sustentadores das atividades econômicas características do período.

Ocorreram profundas transformações nas condutas alimentares destacando-se: a difusão do consumo da carne seca e da carne de charque entre os desbravadores dos sertões; a introdução do pão de farinha de trigo, a famosa combinação do arroz com o feijão, o predomínio do consumo de carne bovina, algumas saladas, o manjar branco e, após a refeição, o café nas mesas das famílias das classes altas e médias. Aos menos afortunados a conduta alimentar predominante era o feijão com farinha de mandioca, o angu de milho e, ocasionalmente a canjica e carnes.

Principalmente nos centros urbanos das regiões sul e sudeste data do final do século XIX e das primeiras décadas do século XX o surgimento das primeiras fábricas de alimentos e a "comida do trabalho". A primeira introduziu e popularizou o macarrão, os molhos e temperos; e a "comida do trabalho", simbolizada pela marmita, popularizou o arroz com feijão, o cozido português (preparado à base de legumes com carne). No cotidiano familiar a conduta alimentar predominante era o arroz com feijão, cozido de carne com legumes, cuscuz, macarrão e paçoca.

A intensificação da imigração, significou a vinda de uma diversidade de grupos étnicos e, gradativamente, foi-se incorporando nas nossas condutas alimentares a esfira, quibe, charuto, o goulash, o frango xadrez, a paella, o puchero, o crepe, o croissant, a pizza, a batata, o sanduíche, o sashimi, o bacalhau, o churrasco, o strogonoff, entre outros. Nos dias de hoje estes pratos estão presentes de norte a sul do país, compondo a dieta do brasileiro e estão disponíveis nos mais diversos pontos de venda como as barracas nas ruas, restaurantes, feiras livres e supermercados.

Um outro determinante a destacar é a família que, conforme é sabido, é o núcleo primário da reprodução, da satisfação das necessidades básicas e da 
socialização de seus membros. Tradicionalmente instituiu-se como papel do homem obter os recursos para a manutenção do seu núcleo e o lar como o lugar da mulher para desempenhar os papéis de aquisição, preparo, distribuição dos alimentos para o consumo e a transmissão e preservação de regras do comensalismo. A cozinha, o ato de cozinhar, servir as refeições constituíam os espaços gregários na conformação de nossas condutas alimentares cujos valores e normas eram transmitidos pela oralidade.

Como os processos sociais não são lineares, as características do desenvolvimento de nossa sociedade sempre colocou a necessidade da inserção da mulher, de crianças e de jovens no mercado de trabalho para complementar a renda principalmente das famílias das classes médias e baixa. Modificam-se os valores e normas conformadores de nossas condutas. A cozinha, o modo de preparo, o ato de comer de espaços gregários vem se tornando self-service à boca do fogão para possibilitar o mirar do inefável aparelho de TV em toda santa refeição.

Pesquisas de opinião pública realizadas ultimamente nas principais capitais do Brasil tem apontado que a renda, a praticidade e o preço tem desempenhado importante papel nas nossas condutas alimentares. Embora observa-se uma crescente preocupação de segmentos da população com a alimentação relacionada com a busca de Qualidade de Vida as publicações especializadas, a escola, os médicos e os nutricionistas são pouco utilizados como fontes de informações sobre questões alimentares. Ao lado disto, o modo como as informações são veiculadas nas embalagens dos produtos, tornando-as cada vez mais parecidas com bulas de remédios, faz com que parcela restrita da população paute suas condutas na escotha alimentar considerando apenas o prazo de validade e a presença de conservantes, predominando como absoluto, na conformação da conduta alimentar, o singelo fator preço. Trabalhos tem mostrado que as nossas condutas alimentares não são muito variadas, predominando como absolutos o, arroz com feijão, bife, massas, batata frita, açucares e refrigerantes. Entre as classes sociais o diferencial passa a ser a quantidade de alimentos e o número de refeições realizadas ${ }^{5}$.

A partir de meados do século atual surge a chamada Terceira Revolução Industrial transformando, profundamente, os modos de produzir, estocar e comercializar os bens e serviços, bem como a composição e o papel até então desempenhado pelos núcleos familiares na conformação das condutas alimentares.
Estas transformações foram possibilitadas pelo aparato tecnológico conquistado com o desenvolvimento da microeletrônica, da informática, da robótica e da telemática.

$\mathrm{Na}$ área dos alimentos e da Alimentação predomina a produção em larga escala; a purificação de frações ou partes de alimentos naturais; a agregação de aditivos; a introdução de múltiplas variações na palatabilidade dos alimentos (mudanças no sabor, na cor, na textura, etc.); a oferta quase que ilimitada de alimentos com sabor doce; a diversidade de fórmulas lácteas industrializadas (que tem sido apontada como responsáveis, nos últimos 40 anos, pela queda alarmante do aleitamento materno) e, mais recentemente, graças à engenharia de alimentos, a oferta de uma infinidade de congelados, semi-prontos, desidratados e liofilizados ${ }^{6,7}$.

No âmbito da comercialização, a partir dos anos 70, proliferam os supermercados e os hipermercados disponibilizando à população produtos alimentícios de todas as regiões do país e de várias partes do mundo ${ }^{8}$.

$\mathrm{O}$ surgimento destes estabelecimentos padronizados tem desempenhado importante papel na uniformização da conduta alimentar, processo que vem sendo garantido pelo suporte da publicidade, principalmente através da televisão.

Estudos tem mostrado que quanto mais se desce na escala da estratificação social maior é a influência exercida principalmente pela televisão nas nossas condutas alimentares. Ela tem se constituído na principal fonte de informações sobre questões alimentares utilizada pela população ${ }^{9}$.

Este veículo de comunicação exerce maior impacto principalmente nas crianças e jovens, razão pela qual grande parte da publicidade de produtos alimentícios é veiculada nos programas direcionados a este segmento de público-alvo.

Em geral os comerciais visam vender marcas e não divulgar informações sobre os produtos.

Autores como Sifontes e Dehollain $(1986)^{9}$ tem alertado para o processo designado de má nutrição comerciogênica, derivado da publicidade veiculada pela televisão que tem induzido a população para um consumo exagerado de alimentos ricos em hidratos de carbono e com alto teor de açúcar, com implicações não apenas no que se refere a um gasto desproporcional de dinheiro na compra destes produtos, mas também no fato de estes alimentos estarem substituindo a compra daqueles de valor nutritivo mais adequados e necessários. Cabe mencionar também o famoso 
cheeseburguer duplo salada com fritas, as pizzas, os salgados acompanhados de sorvete com calda de chocolate, farofa doce e refrigerante, como a paródia do fast-food compondo a conduta alimentar cotidiana de expressivas parcelas de jovens e adultos.

Um outro papel que vem sendo desempenhado pela televisão e por publicações mais direcionadas para o público feminino tem consistido na divulgação de alimentos light e diet, sem contudo diferenciá-los; as dietas da moda propagandeadas por personalidades famosas do mundo artístico, da moda e dos esportes (as dietas da lua; do Dr. Atkins; a de Beverly Hills divulgando fundamentos científicos questionáveis; a 7 Days, de Emerson Fittipaldi) e o preocupante comportamento de resistência ou do desejo culposo de comida popularizado através da conduta da "silhueta de cabide dos manequins" que tem se traduzido como a época das comidas dietéticas, dos complexos vitamínicos, da aeróbica, entre outras, condutas estas orientadas pelo valor do culto ao narcisismo que tem convertido o físico e o que o envolve em símbolo de representação da própria personalidade ${ }^{10}$.

\section{4- CONSIDERAÇÕES FINAIS}

Finalizando, destaco que as colocações aqui apresentadas não significam a não adesão aos avanços científicos e tecnológicos que se presencia na área. O nosso intento foi o de destacar o movimento contraditório de alguns determinantes sociais que agem na conformação da conduta alimentar na direção de uma alimentação adequada ou inadequada e também na produção de uma série de transtornos alimentares, destacando-se a obesidade, a anorexia e a bulimia.

Há que se pensar na busca de garantia do direito à alimentação de qualidade para todos os seres humanos, o que pressupõe a construção de um novo paradigma de sociedade que enfrente e supere as distorções que caracterizam o atual modelo de desenvolvimento dominante na sociedade brasileira e que se direcione na construção de um país com mais equidade e justiça social. A sociedade não pré-existe aos homens, ela se faz a partir e através das práticas humanas cotidianas. Nesse sentido, os profissionais da área tem que direcionar as suas ações norteadas por um paradigma que privilegie estratégias para a transformação das relações humanas na direção da constituição de uma consciência coletiva concretizadora dos ideais da cidadania, dos quais o acesso aos alimentos e à alimentação nutricionalmente adequados são um de seus elementos constitutivos.

Alessi NP. Food behavior and society. Medicina (Ribeirão Preto) 2006; 39 (3): 327-32.

ABSTRACT: This paper begins with the concept that behaviors or food patterns are historically determined. Contextualize the main characteristics of several phases of the development of the Brazilian society and identify the values and the social norms responsible for predominant food patterns in each of the different phases of the Brazilian development. In the second part emphasizes as the main changes in the labor market and in the mass media communication, the so called "third industrial revolution", have contributed to the construction of non-healthy food patterns notconducive to the contemporary search for quality of life.

Keywords: Food Consumption. Food Habits.

\section{REFERÊNCIAS}

1 - Oliveira SP, Thébaud-Mony A. Estudo de consumo alimentar: em busca de uma abordagem multidisciplinar. Rev Saúde Pública 1997; 31: 201-8.

2 - Rosales C G-H, Figueroa MAH. !A Comer! Alimentación y cultura. Madrid: Raycar; 1988.
3 - Folha de São Paulo. O tabuleiro do Brasil 500. Caderno Especial. Domingo, 2 de abril de 2000.

4 -Camara Cascudo L. História da alimentação no Brasil. Belo Horizonte: Itatiaia; São Paulo: EDUSP; 1983.

5 - Dutra de Oliveira JE, Cunha SFC, Marchini JS. A desnutrição dos pobres e dos ricos: dados sobre a alimentação no Brasil. São Paulo: Sarvier; 1996. 
6 - Jaffé, W. G. La evolución de la alimentación humana. Arch Latinoam Nutr 1981; 31 (1): 13-24.

7 - Casotti L, Thiollent M. Comportamento do consumidor de alimentos: informações e reflexões. Rio de Janeiro: COPPEAD/ UFRJ, s.d.

8 - Martinelli JO. A globalização e a indústria alimentar: um estudo a partir das grandes empresas. Marília: UNESP; São Paulo: FAPESP, 1999.
9 - Sifontes MZM, Dehollain PL. Efecto de los medios de comunicacion social el la aquisición de alimentos a nivel familiar. Arch Latinoam Nutr 1986; 36 (1): 166-86.

10 - Alcedo M. Anorexia y bulimia: enfermedades de género, enfermedades de la cultura. In: Alimentación y cultura. Actas del Congresso Internacional. Espanha: Ediciones La Val de Onsera; 1999. v. 1. 